\title{
Offshore AC Fault Protection of Diode Rectifier Unit Based HVDC System for Wind Energy Transmission
}

\author{
Rui Li, Lujie Yu, and Lie Xu, Senior Member, IEEE
}

\begin{abstract}
Offshore AC fault protection of wind turbines (WTs) connecting with diode rectifier unit based HVDC (DRU-HVDC) system is investigated in this paper. A voltage-error-dependent fault current injection is proposed to regulate the WT current during offshore AC fault transients and quickly provide fault current for fault detection. Considering different fault locations, the fault characteristics during symmetrical and asymmetrical faults are presented and the requirements for fault detection are addressed. A simple and effective offshore AC fault protection solution, combining both overcurrent protection and differential protection, is proposed by utilizing the developed fast fault current providing control. To improve system availability, reduced DC voltage of the DRU-HVDC system is investigated, where one of the series-connected DRUs is disconnected and the onshore modular multilevel converter (MMC) actively reduces DC voltage to resume wind power transmission. The proposed scheme is robust to various offshore AC faults and can automatically restore normal operation. Simulation results confirm the proposed fault protection strategy.
\end{abstract}

Index Terms - diode rectifier unit based HVDC (DRU-HVDC), fault protection, HVDC transmission, offshore wind farm, symmetrical and asymmetrical AC faults.

\section{INTRODUCTION}

$\mathrm{W}$ ith the fast development of the high voltage DC (HVDC) technology based on voltage-source-converters (VSCs), offshore wind power will play an important role in the Europe electricity market in the near future [1-3]. To reduce the cost related to offshore wind power integration, the diode rectifier unit based HVDC (DRU-HVDC) has recently received notable interests [4-10]. By replacing the VSC offshore station with diode rectifier, the transmission loss and the total cost can be potentially reduced by up to $20 \%$ and $30 \%$ respectively while the transmission capacity can be increased by a third $[5,11]$. In addition, the volume and weight of the platform are reduced by $80 \%$ and two thirds respectively. It also has the advantages of high reliability, modular design, full encapsulation, as well as less operation and maintenance cost, etc. $[5,11]$.

Reference [4] presents a voltage and frequency control of the offshore wind turbines (WTs) connected with DRU-HVDC system and proves that such solution is technically feasible in

The work is supported in part by the European Union's Horizon 2020 research and innovation program under grant agreement No 691714.

The authors are with the Department of Electronic and Electrical Engineering, University of Strathclyde, Glasgow, G1 1XW UK (e-mail: rui.li@strath.ac.uk, lujie.yu@strath.ac.uk, lie.xu@strath.ac.uk). steady states and during transients. In [8], the developed control scheme is further tested during three-phase faults at the AC terminals of the onshore station and validates that the DRUHVDC is robust to such onshore AC faults. However, the measurements at the point of common connection (PCC) are required for each WT, necessitating the need for high-speed communication.

Various fault cases, including DC faults, symmetrical onshore and offshore AC faults, are investigated in [9]. However, during offshore AC fault, the AC currents of the WT converters are simply controlled at zero without considering the need for the operation of the protection relays. Reference [10] introduces an energy management scheme to regulate the input and output power of the DRU-HVDC link and verifies its low voltage ride-through (LVRT) capability. However, the WTs are modelled as ideal voltage source and the interaction between the WTs and DRU stations are ignored.

In [12], the $d q$ reference frame is directly obtained by integrating the desired frequency (e.g. $50 \mathrm{~Hz}$ ) and thus the offshore frequency is fixed at $50 \mathrm{~Hz}$ during the offshore AC fault. However, the offshore wind farms (OWFs) are simplified as controllable current sources and the dynamics of the WT converters are omitted. A distributed phase locked loop (PLL) based control is proposed in [13] to shared reactive power among WTs without communication. With the developed controller, the system can ride-through onshore and offshore AC faults but the fault detection is not addressed.

The paper investigates offshore AC fault protection of DRUHVDC system considering WT control and operation requirement during symmetrical and asymmetrical offshore AC faults. The main contributions of this paper are:

- Combined with WT control strategies during normal operation for DRU-HVDC system, a voltage-errordependent fault current injection is proposed to regulate the WT current during offshore AC fault transients and quickly provide fault current for fault detection.

- Considering different fault locations, the fault characteristics during symmetrical and asymmetrical offshore AC faults are presented and the requirements for fault detection are addressed.

- A simple and effective offshore AC fault protection solution for a DRU-HVDC connected wind farm, combining both overcurrent protection and differential protection, is proposed by utilizing the developed fast fault current providing control. 
This paper is a post-print of a paper submitted to and accepted for publication in IEEE Transaction on Industrial Electronics and is subject to Institution of Electrical and Electronic Engineering Copyright. The copy of record is available at IEEE Xplore Digital Library.

- Reduced DC voltage of the DRU-HVDC system is investigated, where one of the series-connected DRUs is disconnected and the onshore modular multilevel converter (MMC) actively reduces DC voltage to resume wind power transmission, leading to improved system availability.

The paper is organized as follows. In Section II, the layout of the offshore wind power system with DRU-HVDC is described. Combined with WT control strategies during normal operation, the voltage-error-dependent fault current injection is proposed in Section III. In Section IV, the fault characteristics during symmetrical and asymmetrical offshore AC faults are addressed and the offshore AC fault protection solution combining both overcurrent protection and differential protection is developed. The proposed control and fault protection scheme is assessed in Section V, considering both symmetrical and asymmetrical offshore faults. Finally Section VI draws the conclusions.

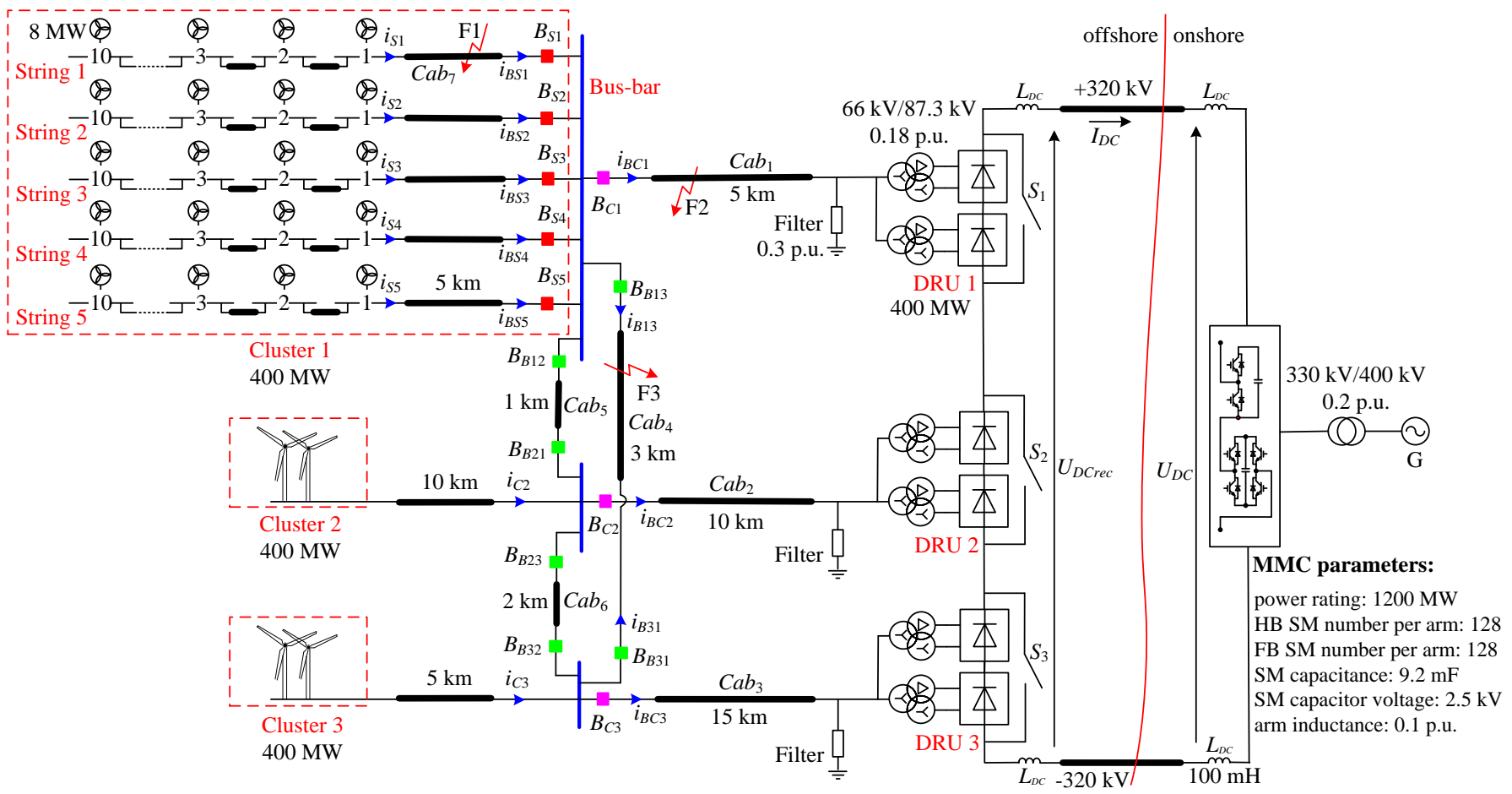

Fig. 1. Layout of the offshore wind power system with DRU-HVDC.

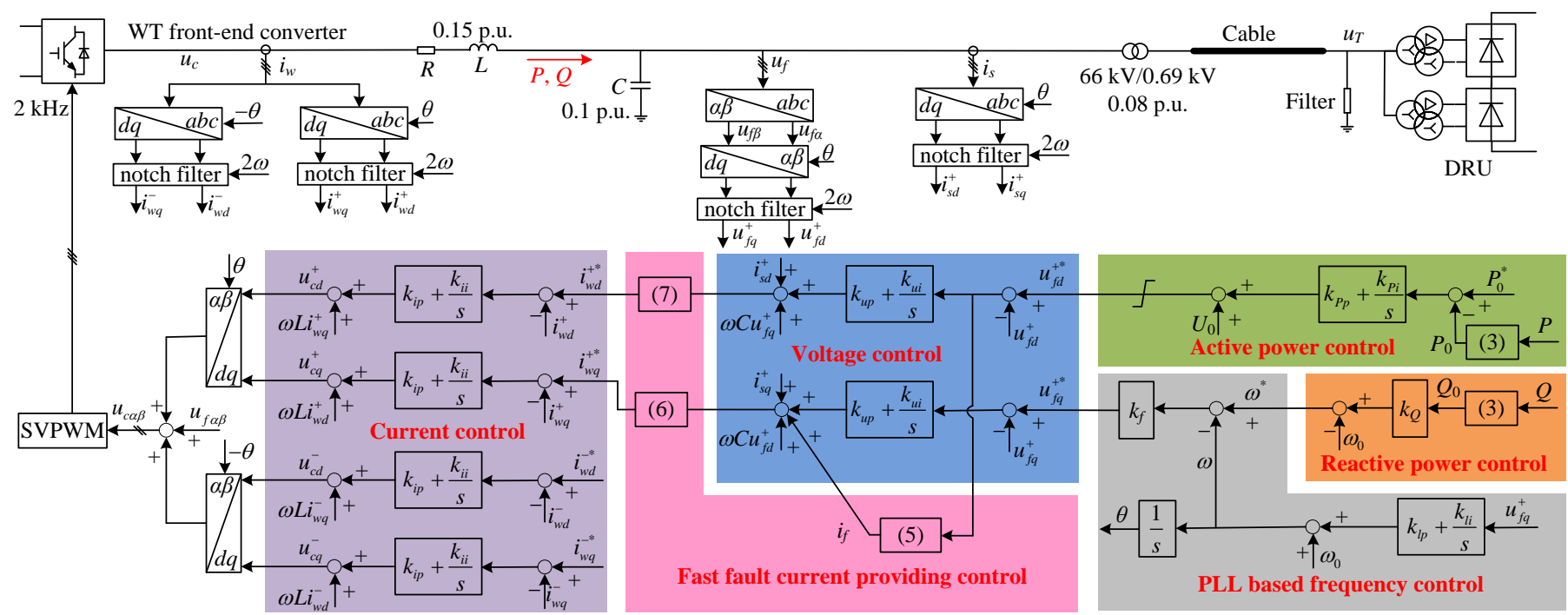

Fig. 2. Control strategy of offshore WT front-end converters connected with DRU-HVDC.

\section{SYSTEM CONFIGURATION}

The layout of the offshore wind power transmission system with DRU-HVDC is illustrated in Fig. 1, which consists of three WT clusters but only Cluster 1 shows the details for simplicity.
Each cluster is made up of $5 \mathrm{WT}$ strings and each string contains ten $8 \mathrm{MW}$ WTs based on permanent magnet synchronous generators (PMSGs) [14-16].

To enable encapsulation, easy transportation, and stepwise offshore platform installation, series connection of the DRUs is 
This paper is a post-print of a paper submitted to and accepted for publication in IEEE Transaction on Industrial Electronics and is subject to Institution of Electrical and Electronic Engineering Copyright. The copy of record is available at IEEE Xplore Digital Library.

adopted as shown in Fig. 1, where three DRUs are connected in series on the DC side to boost DC voltage while the AC sides are parallel connected to the wind farm clusters [11, 17]. Each DRU is made up of two series connected 12-pulse bridges with star-star-delta three-winding transformers on AC side. Filters are connected on the AC side of each DRU for reactive power compensation and harmonic suppression.

The hybrid MMC with mixed half-bridge (HB) and fullbridge (FB) submodules (SMs) in each arm is adopted for the onshore station [18], which regulates the DC voltage and allows reduced DC voltage operation of the DRU-HVDC link in the event of disconnecting one DRU, which will be demonstrated in Section V.

\section{Distributed CONTROL STRATEGY OF OFFSHORE WT FRONT END CONVERTERS}

In DRU connected OWFs, the WT generator side converters operate on DC voltage control mode while the front-end converters (FECs) control the offshore AC voltage and frequency, as well as the generated power of WTs $[4,8]$. The distributed control strategy with fast fault current providing capability and negative-sequence current control function as shown in Fig. 2 is presented in this section, including the current loop, AC voltage magnitude and frequency control, and active and reactive power control. In order to regulate the FECs' current during offshore AC faults including asymmetrical fault, both positive- and negative-sequence currents have to be controlled.

\section{A. Current Control}

The current controller is developed in double synchronous reference frame to effectively suppress the negative-sequence currents during asymmetrical offshore AC faults. In positiveand negative-sequence reference frames, the dynamics of the current loops are given by

$$
\begin{aligned}
& {\left[\begin{array}{l}
u_{c d}^{+} \\
u_{c q}^{+}
\end{array}\right]=\left[\begin{array}{l}
u_{f d}^{+} \\
u_{f q}^{+}
\end{array}\right]+L \frac{d}{d t}\left[\begin{array}{l}
i_{w d}^{+} \\
i_{w q}^{+}
\end{array}\right]+R\left[\begin{array}{c}
i_{w d}^{+} \\
i_{w q}^{+}
\end{array}\right]+L\left[\begin{array}{cc}
0 & -\omega \\
\omega & 0
\end{array}\right]\left[\begin{array}{l}
i_{w d}^{+} \\
i_{w q}^{+}
\end{array}\right]} \\
& {\left[\begin{array}{l}
u_{c d}^{-} \\
u_{c q}^{-}
\end{array}\right]=\left[\begin{array}{l}
u_{f d}^{-} \\
u_{f q}^{-}
\end{array}\right]+L \frac{d}{d t}\left[\begin{array}{l}
i_{w d}^{-} \\
i_{w q}^{-}
\end{array}\right]+R\left[\begin{array}{l}
i_{w d}^{-} \\
i_{w q}^{-}
\end{array}\right]+L\left[\begin{array}{cc}
0 & -\omega \\
\omega & 0
\end{array}\right]\left[\begin{array}{l}
i_{w d}^{-} \\
i_{w q}^{-}
\end{array}\right]}
\end{aligned}
$$

where the superscripts ' + ' and '-' denote the positive- and negative-sequence components in positive- and negativesequence $d q$ reference frames, respectively. Notch filters as shown in Fig. 2 are used to remove the second-order components and the transfer function is:

$$
G(s)=\frac{s^{2}+4 \omega^{2}}{s^{2}+4 \zeta \omega s+4 \omega^{2}}
$$

where $s$ is the Laplace operator; $\omega$ is the offshore grid angular velocity; and $\zeta$ is the damping ratio. The positive- and negative-sequence current controllers implemented in the positive- and negative-sequence $d q$ frames are used [2] and the structure is shown in Fig. 2. As the system dynamics for the positive and negative sequences are identical, their current controllers are thus designed with the same parameters [19].

The positive-sequence current references $i_{w d}^{+*}$ and $i_{w q}^{+*}$ are set by the offshore AC control loop, as will be presented in next subsection. With the negative-sequence current references $i_{w d d}^{-*}$ and $i_{w q}^{-*}$ simply set at zero, the WT currents are largely balanced during an asymmetrical offshore fault, which avoids converter overcurrent and WTs can remain operational to actively provide fault current to enable fault detection and protection

\section{B. Fast Fault Current Providing Control}

To enable fault detection for protection relays, the WT converters need to remain operational and provide fast fault current response during faults. Considering the most severe fault case, where the offshore voltage largely drops to zero, the WT converters are unable to transmit active power to the DRUHVDC link. Thus the $d$-axis current needs to be reduced while the $q$-axis current is quickly increased to provide fault current to the offshore network. An additional component $i_{f}$ is thus added to the output of the $q$-axis voltage loop to increase the $q$ axis current, as shown in Fig. 2 and (4):

$$
i_{w q}^{+^{*}}=k_{u p}\left(u_{f q}^{+^{*}}-u_{f q}^{+}\right)+k_{u i} \int\left(u_{f q}^{+^{*}}-u_{f q}^{+}\right) d t+i_{s q}^{+}+\omega C u_{f d}^{+}+i_{f} .
$$

The profile of the voltage-error-dependent fault current $i_{f}$ is defined as (5) and illustrated in Fig. 3:

$$
i_{f=} \begin{cases}0, & \left(u_{f d}^{+*}-u_{f d}^{+}\right) \leq U_{\text {error } 1} \\ \frac{I_{\max }}{U_{\text {error } 2}-U_{\text {error } 1}}\left[\left(u_{f d}^{+*}-u_{f d}^{+}\right)-U_{\text {error } 1}\right], & U_{\text {error } 1}<\left(u_{f d}^{+*}-u_{f d}^{+}\right) \leq U_{\text {error } 2} . \\ I_{\max }, & U_{\text {error } 2}<\left(u_{f d}^{+*}-u_{f d}^{+}\right)\end{cases}
$$

During normal operation, the $d$-axis voltage $u_{f q}^{+}$follows the reference $u_{f q}^{+*}$ and the voltage error $u_{f q}^{+*}-u_{f q}^{+}$is around zero, leading to zero fault current $\left(i_{f}=0\right)$. During the fault, the $d$-axis voltage loop saturates and the voltage error increases. Once $u_{f d}^{+*}-u_{f d}^{+}$is over the lower threshold $U_{\text {error } 1}, i_{f}$ starts to increase. The WT converters provide maximum current $\left(i_{f}=I_{\max }\right)$ after the voltage error becoming greater than the upper threshold $U_{\text {error } 2}$. After fault isolation, the offshore network voltage is restored and subsequently $i_{f}$ is gradually reduced. The upper threshold $U_{\text {error } 2}$ is set at 0.8 p.u. in this paper to ensure the WT converters provide maximum current $\left(i_{f}=I_{\max }\right)$ during offshore AC faults which results in considerable residual voltage due to the voltage drop on the system impedance. During transients, the voltage feedback could deviate from the reference, leading to voltage errors. The lower threshold $U_{\text {error } 1}$ is thus set at 0.5 p.u. in this paper to avoid false trigger of fast fault current control under such transients. Also, the fault currents provided by the WT converters are increased in the rate defined by $U_{\text {error } 1}$ and $U_{\text {error } 2}$ and the disturbance on the system incurred by the current step is thus avoided.

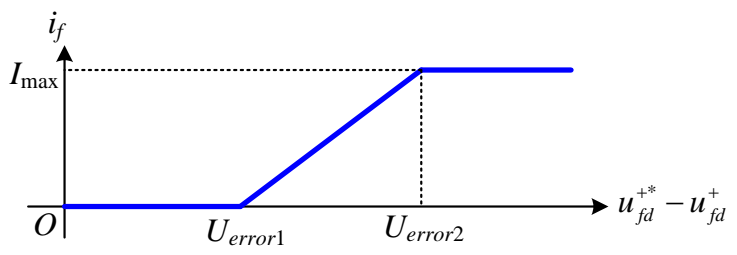

Fig. 3. Voltage-error-dependent fault current profile.

To ensure the WT converter current does not exceed its maximum value, and considering the need for the converter to 
This paper is a post-print of a paper submitted to and accepted for publication in IEEE Transaction on Industrial Electronics and is subject to Institution of Electrical and Electronic Engineering Copyright. The copy of record is available at IEEE Xplore Digital Library.

provide the $q$-axis fault current, the current limit for the $d$-axis current needs to be set dynamically. The upper and lower limits for the $d$ - and $q$-axis currents are set as:

$$
\begin{gathered}
i_{\text {wqUpper }}^{+*}=k_{o} I_{\text {rated }}, \quad i_{\text {wqLower }}^{+*}=-k_{o} I_{\text {rated }} \\
i_{\text {wdUpper }}^{+*}=\sqrt{\left(k_{o} I_{\text {rated }}\right)^{2}-\left(i_{w q}^{+*}\right)^{2}}, \quad i_{\text {wdLower }}^{+*}=0
\end{gathered}
$$

where $I_{\text {rated }}$ is the converter rated current and $k_{o}$ defines the overload capability of the converters and is set at 1.3 in this paper. The converter overcurrent protection threshold is dependent on the converter design and a value of 2 p.u. is typical over which the converters need to be blocked to avoid damage [20-22]. With the current limit set at 1.3 p.u. in this paper, the WT converters continuously operate without damage while various faults can still be detected by the proposed fault detection scheme, as will be demonstrated in Section V. As the active power can only flow from WTs to the offshore network, the lower limit of the positive-sequence $d$-axis current $i_{w d L o w e r}^{+*}$ is set at zero in (7) in order to avoid active power circulation among WT converters. Thus, with the increase of $i_{w q}^{+*}$, the $d$-axis current reference $i_{w d}^{+^{*}}$ reduces according to the dynamic limit depicted by (7) to avoid converter overcurrent.

In the event of a severe offshore AC fault, the offshore grid voltage drops and WT FECs immediately provide $q$-axis (reactive) fault currents with the proposed control scheme. Due to the reduced offshore voltage, the active power that can be transmitted by the WT FECs is significantly reduced and the active power control loop saturates. In DRU connected OWFs, the WT generator-side converters operate on DC voltage control mode $[4,8]$ and force the generator to reduce the generated active power to avoid overvoltage of the DC link. With such control scheme, the DC voltage of the WT converter can still be controlled around the rated value, which enables the low voltage ride-through (LVRT) capability of PMSG based wind power system [23-25]. The resultant active power surplus leads to the increase of the speed of the generator and thus pitch control is used to reduce the captured wind power and avoid over-speed of WT generators [26, 27].

As the DC voltage can be controlled around the rated value during AC faults, the FECs are still capable of outputting the required $\mathrm{AC}$ voltage and the generator-side converters do not have direct influence on the behavior of the offshore AC network, which is the focus of this paper. The generator-side converter is thus simplified as a DC voltage source for simulation acceleration $[4,8,24]$.

\section{Voltage Control}

The offshore AC voltage magnitude needs to be properly regulated. Considering asymmetrical faults, the negativesequence currents are controlled to zero. This means that only positive-sequence voltage can be actively controlled whereas the negative-sequence voltage is determined by the fault impedance. The dynamics of the positive-sequence voltage loops are given by

$$
\left[\begin{array}{c}
i_{w d}^{+} \\
i_{w q}^{+}
\end{array}\right]=\left[\begin{array}{c}
i_{s d}^{+} \\
i_{s q}^{+}
\end{array}\right]+C \frac{d}{d t}\left[\begin{array}{l}
u_{f d}^{+} \\
u_{f q}^{+}
\end{array}\right]+C\left[\begin{array}{cc}
0 & -\omega \\
\omega & 0
\end{array}\right]\left[\begin{array}{l}
u_{f d}^{+} \\
u_{f q}^{+}
\end{array}\right] .
$$

The voltage control loop sets the current references and may saturate during offshore AC faults. Under such conditions, the WT converters operate on current limiting mode to provide fault current.

\section{Active Power Control}

As only the positive-sequence voltage is controlled and the voltage vector is aligned on the $d$-axis by PLL, the positivesequence $d$-axis voltage $u_{f d}^{+}$is used to regulate the active power transferred to the DRU-HVDC link and its reference $u_{f d}^{+*}$ is thus set by the active power controller as:

$$
u_{f d}^{+*}=U_{0}+k_{P p}\left(P_{0}^{*}-P_{0}\right)+k_{P i} \int\left(P_{0}^{*}-P\right) d t
$$

where $U_{0}$ is the start-up voltage and set at 0.8 p.u. to build up the offshore AC voltage while avoid the conduction of the DRU. The $d$-axis voltage reference is in the range of 0.8-1.1 p.u. The WT FECs in DRU connected OWFs can accurately track active power using maximum power point tracking (MPPT) technology in normal operation [23, 24, 28]. During fault, the active power loop may saturate and the offshore voltage amplitude reference is limited at 1.1 p.u.

\section{E. Offshore Frequency and Reactive Power Control}

PLL is an important part of the WT converter control system, which derives the offshore network angle (frequency) for $a b c / d q$ reference frame transformation and reactive power sharing among WT converters. The frequency loop considers the operating principle of the PLL, which measures the $q$-axis voltage $u_{f q}^{+}$and drives the offshore frequency $\omega$ to obtain zero $u_{f q}^{+}$, as depicted by Fig. 2 and (10):

$$
\omega=\omega_{0}+k_{l p} u_{f q}^{+}+k_{l i} \int u_{f q}^{+} d t
$$

where $\omega_{0}$ is the rated frequency of the offshore network.

The $q$-axis voltage reference $u_{f q}^{+*}$ is set by the frequency loop and feeds to the AC voltage loop to regulate the offshore $\mathrm{AC}$ frequency:

$$
u_{f q}^{+*}=k_{f}\left(\omega^{*}-\omega\right) .
$$

With the PLL based frequency control, the offshore frequency $\omega$ follows the reference $\left(\omega=\omega^{*}\right)$ while the $q$-axis voltage $u_{f q}^{+}$is well regulated at zero [13, 29].

As shown in Fig. 2, the reactive power frequency $(Q-f)$ droop is adopted to share reactive power among WT converters and set the frequency reference $\omega^{*}[4,5,30,31]$ :

$$
\omega^{*}=\omega_{0}+k_{Q} Q_{0} \text {. }
$$

All the WT FECs uniformly adopt the developed control scheme, where only the local measurements are required, and can automatically ride-through the fault, as will be presented in Section V.

\section{OFFSHORE AC FAULT PROTECTION}

The power electronics devices used in the converters have limited overcurrent capability and are vulnerable to large fault currents. As described in Section III B, to avoid converter damage, the overcurrent protection threshold is typically set at 
This paper is a post-print of a paper submitted to and accepted for publication in IEEE Transaction on Industrial Electronics and is subject to Institution of Electrical and Electronic Engineering Copyright. The copy of record is available at IEEE Xplore Digital Library.

2 p.u. over which the converters need to be blocked [20-22, 32]. In the proposed scheme, the converter currents are controllable during various faults and are limited to 1.3 p.u. to ensure safe operation of the converters and enable offshore AC fault detection.

Due to the use of DRUs at offshore and the limited fault current providing capability of WT converters, design of offshore AC protection for DRU connected wind farms is different to that of conventional $\mathrm{AC}$ grid and offshore wind farms connected by either HVAC or VSC HVDC transmission system.

\section{A. Layout of Protection Circuit Breakers}

To examine the coordination of the WT control (providing fault currents) and the fault detection scheme, a simplified layout of the protection breakers and their connection to the DRU system is shown in Fig. 1. The main protection can be divided into the following three categories:

- WT string: Each string is connected to the cluster bus-bar through circuit breaker $B_{S j}(j=1,2, \ldots, 5)$ to isolate the faulty string from the $\mathrm{AC}$ network and ensure adequate system recovery for the healthy network. For example, the fault case F1 occurred in String 1 should lead to the opening of breaker $B_{S 1}$ to isolate the faulty String 1 from the rest of the network.

- Cluster interconnection: The three clusters are interconnected together through three AC cables $\left(\mathrm{Cab}_{4}\right.$, $C a b_{5}$, and $C a b_{6}$ ) with each end equipped with breakers to isolate the fault (F3, Fig. 1) at the ring cluster interconnection cables.

- WT cluster: Breaker $B_{C j}(j=1,2,3)$ is equipped at one end of the cluster cable $\left(C a b_{1}, C a b_{2}\right.$, and $C a b_{3}$, Fig. 1) near the cluster bus-bar to isolate the fault (F2, Fig. 1) occurred at cluster cables from the wind farm.

Considering the fault (F2, Fig. 1) applied at $C a b_{1}$, breaker $B_{C 1}$ opens to disconnect $C a b_{1}$ and then the wind power of Cluster 1 can be transmitted to onshore by the DRUs 2 and 3 through the ring cluster interconnection cables. To enable such power transfer, the DRU-HVDC link is operated with reduced DC voltage $\left(2 / 3 U_{D C}\right)$ regulated by the onshore hybrid MMC station. The DRU connected with the faulty branch (DRU 1, Fig. 1) is bypassed by the DC switch $\left(S_{1}\right.$, Fig. 1$)$ to reduce the conduction losses resulting from the power flow through the faulty DRU.

After the reduction of the DC voltage, the maximum power transmission capability of the DRU-HVDC system is reduced to 0.67 p.u. To ensure DC current does not exceed the maximum value, the onshore MMC sets a maximum DC current order and if the current exceeds the maximum value, the DC voltage will increase slightly to automatically limit the power transmitted from the WTs [33]. In the meantime, the WTs will limit the generated power through pitch control. After the disconnection of the cluster cable, this arrangement is able to transmit certain wind power through the healthy parts and thus the system availability is improved.

\section{B. Overcurrent Protection for Symmetrical Fault}

\section{1) String fault:}

Although wind turbine FECs have limited fault current capability (e.g. 1.3 p.u. in this paper), during a fault on one of the turbine strings, substantial overcurrent will still be present as all the other turbines will feed fault current to the faulty string.

Considering fault case F1 applied at string cable $\mathrm{Cab}_{7}$ as shown in Fig. 1, in addition to Clusters 2 and 3, other healthy Strings 2, 3, 4, and 5 provide fault currents for breaker $B_{S 1}$, as the FECs of all the WTs operate on current limiting mode during the fault:

$$
i_{B S 1}=-i_{C 2}-i_{C 3}-\sum_{j=2}^{5} i_{S j} .
$$

The current flowing through $B_{S 1}$ reverses after the fault and is much higher than the nominal current. Thus, overcurrent protection can be adopted to open $B_{S 1}$ and isolate the fault. The breakers on the healthy strings $\left(B_{S 2}-B_{S 5}\right)$ do not experience overcurrent and thus remain closed:

$$
i_{B S j}=i_{S j}, \quad j=2,3,4,5 .
$$

The currents flowing through cluster breakers $\left(B_{C 1}-B_{C 3}\right)$ reduce to around zero after the solid symmetrical fault and $B_{C 1^{-}}$ $B_{C 3}$ also remain closed.

\section{2) Cluster fault:}

Considering fault case F2 applied at the cluster cable $C a b_{1}$ as illustrated in Fig. 1, the circuit breakers on strings $\left(B_{S 1}-B_{S 5}\right)$ do not suffer any overcurrent due to the current limit capability of the wind turbine FECs:

$$
i_{B S j}=i_{S j}, \quad j=1,2, \ldots, 5 .
$$

However, as expressed by (16), breaker $B_{C 1}$ on the faulty cluster cable experiences overcurrent provided by the three clusters and can be opened by overcurrent protection mechanism:

$$
i_{B C 1}=i_{C 2}+i_{C 3}+\sum_{j=1}^{5} i_{S j}
$$

Due to the unidirectional characteristics of DRUs, the currents flowing through breakers on healthy cables $\left(B_{C 2}\right.$ and $\left.B_{C 3}\right)$ are reduced to around zero during the fault and thus they remain closed. The system is then operated with reduced DC voltage $\left(2 / 3 U_{D C}\right)$ as previously discussed.

By measuring overcurrent and properly setting the thresholds, the faulty string or cluster can be accurately located and the corresponding circuit breaker is selectively opened to isolate the fault. Overcurrent protection provides a relatively simple and reliable approach for the OWFs connecting with DRU-HVDC system.

The ring arrangement of cables $\mathrm{Cab}_{4}, \mathrm{Cab}_{5}$, and $\mathrm{Ca} \mathrm{b}_{6}$ provides multiple power transmission paths and reduces the potential wind energy loss during the aforementioned cluster faults. In addition, the interconnection of the clusters ensures almost identical voltages at the DRU AC terminals, leading to DC voltage sharing among the DRUs. As the same DC current flows through the series connected DRUs, the active power is also shared. The ring connection of the clusters improves the system reliability and its fault protection will be considered in the following Subsection D. 
This paper is a post-print of a paper submitted to and accepted for publication in IEEE Transaction on Industrial Electronics and is subject to Institution of Electrical and Electronic Engineering Copyright. The copy of record is available at IEEE Xplore Digital Library.

\section{Overcurrent Protection for Asymmetrical Fault}

The cluster cable fault F2 is considered in this subsection to demonstrate the overcurrent protection for asymmetrical faults. During an asymmetrical fault, the output current of the wind farm is distributed among the cluster breakers:

$$
i_{B C 1}=i_{C 2}+i_{C 3}+\sum_{j=1}^{5} i_{S j}-i_{B C 2}-i_{B C 3} \text {. }
$$

- Current in the faulty phase of cluster breaker: For the faulty phase, the wind farm currents partially flow to the DRU stations through the cluster breakers while the dominant part feeds to the fault. The currents mainly flow through the breaker $B_{C 1}$ on the faulty cluster and thus $B_{C 1}$ experiences overcurrent and can be opened.

- Current in the healthy phase of cluster breaker: The wind farm currents of the healthy phase are still largely shared among the cluster breakers $B_{C j}(j=1,2,3)$ and flow to the DRU station.

- String breaker currents: As the proposed control can effectively suppress the negative-sequence currents during asymmetrical faults, the currents flowing through the string breakers $B_{S 1}-B_{S 5}$ are largely balanced and can still be expressed by (15). Thus, $B_{S 1}-B_{S 5}$ do not experience overcurrent during cluster cable fault F2 and remain closed. During an asymmetrical fault, the current of the faulty phase has similar behaviors as that during symmetrical fault while the current of the healthy phase still largely flows to the DRU station. Thus, the circuit breaker on the faulty cable detects overcurrent on the fault phase and can activate accordingly.

\section{Differential Protection for Offshore Fault at Cluster Interconnection Cable}

During normal operation, the currents flowing through the interconnection cables $\left(\mathrm{Ca}_{4}, \mathrm{Ca} \mathrm{b}_{5}\right.$, and $\left.\mathrm{Ca} b_{6}\right)$ depend on the power differences among the three clusters and the AC cable impedances, and thus are usually low. During a fault (F3, Fig. 1) at the cluster interconnection cable, the power of the three clusters flows to the fault through the ring connection of cables $C a b_{4}, C a b_{5}$, and $C a b_{6}$, which experience large fault currents. Differential protection scheme is thus adopted for the ring connection of cables $C a b_{4}, C a b_{5}$, and $C a b_{6}$, where the currents flowing into and out of the cables are compared and a fault is detected if the current difference is out of the protection range. Considering cable $\mathrm{Cab}_{4}$ as shown in Fig. 1 and ignoring distributed capacitance currents, when no fault is present, the currents at both ends of $\mathrm{Cab}_{4}\left(i_{B 13}\right.$ and $\left.i_{B 31}\right)$ have the same magnitude but with opposite polarity. In this case, the sum of $i_{B 13}$ and $i_{B 31}$ is null. On the other hand, when the fault F3 occurs, the currents provided by WT converters with the proposed control flow into the cable at both ends and thus the sum of $i_{B 13}$ and $i_{B 31}$ is not zero and exceeds the protection threshold. In reality, the offshore AC cables have higher distributed capacitance, and thus the protection range needs to be properly set to avoid mal-operation of differential protection under external fault [34, 35].

During the fault at cluster interconnection cable, the string breakers $\left(B_{S 1}-B_{S 5}\right)$ and the cluster breakers $\left(B_{C 1}-B_{C 3}\right)$ do not experience overcurrent due the current limiting capability of
WTs and the unidirectional characteristics of DRUs and thus remain closed. After the fault (F3) is isolated by circuit breakers $\left(B_{B 13}\right.$ and $\left.B_{B 31}\right)$, wind power transmission resumes.

\section{SimUlation}

The proposed control and protection scheme is assessed using the model shown in Fig. 1 in PSCAD X4 with parameters of the WT FECs depicted in Fig. 2. To test the system performances during an offshore AC fault at a string, the fault string (String 1, Fig. 1) is represented by a lumped converter of $80 \mathrm{MW}$ (Converter 1) while the other healthy strings in Cluster 1 (Strings 2-5) and Clusters 2 and 3 are modelled as lumped converters rated at $320 \mathrm{MW}, 400 \mathrm{MW}$, and $400 \mathrm{MW}$ (Converters 2, 3, and 4), respectively, as illustrated in Fig. 4. The generator-side converter is simplified as a DC voltage source of $1100 \mathrm{~V}[4,8]$ while the aggregated FECs and the DRU station are represented by detailed switching models. The onshore hybrid MMC station is represented by detailed submodule-based switching function model [36].

The three-phase fault model in PSCAD library is used for generating symmetrical or asymmetrical faults on the offshore network. The fault types are internally configured as threephase fault and phase-to-phase (phase $a$-to- $b$ ) fault respectively for the tested symmetrical or asymmetrical faults. The fault off and on resistances are set at $10 \mathrm{M} \Omega$ and $3.6 \mathrm{~m} \Omega$ respectively to represent the cleared state of the fault and the branch resistance during a solid faulted state. A timed fault logic component is used to automatically apply a permanent fault occurring at $t=0.3$ S.

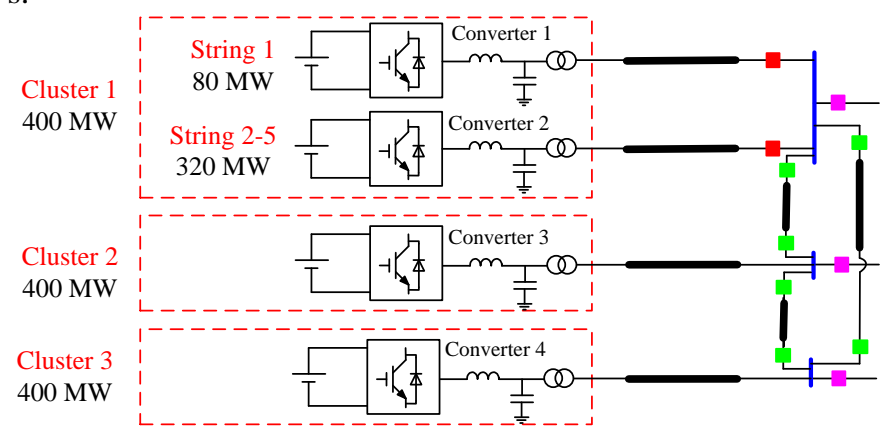

Fig. 4. Aggregated offshore wind farm model.

TABLE I

Control Parameters of the Tested System.

\begin{tabular}{l|l|l}
\hline \hline Components & Parameters & Values \\
\hline Current controller & $k_{i p ;} k_{i i}$ & $1.5 ; 30$ \\
\hline Voltage controller & $k_{u p ;} k_{u i}$ & $0.3 ; 5$ \\
\hline PLL & $k_{l p ;} k_{l i}$ & $0.4 ; 12$ \\
\hline Active power controller & $k_{P p} k_{P i}$ & $3 ; 550$ \\
\hline Reactive power controller & $k_{Q}$ & 0.02 \\
\hline Frequency controller & $k_{f}$ & 50 \\
\hline \hline
\end{tabular}

Three-phase breaker model in PSCAD library is used to simulate three-phase circuit breaker operation. Breaker open resistance is set at $1000 \mathrm{M} \Omega$ to represent the off (open) state of the breaker and breaker close resistance is set at $1 \mathrm{~m} \Omega$ to represent the on (closed) state of the breaker. This component is controlled through a timed breaker logic component to simplify the open and close of the breaker at user specified times. The 
This paper is a post-print of a paper submitted to and accepted for publication in IEEE Transaction on Industrial Electronics and is subject to Institution of Electrical and Electronic Engineering Copyright. The copy of record is available at IEEE Xplore Digital Library.

breakers are initially set to on (closed) and when the breaker open signal is activated (specified at $t=0.55 \mathrm{~s}$ in this paper for illustration), the breaker will open at the first current zero point.

Small-signal modelling method is used for tuning WT control parameters, where the eigenvalues of the linearized small-signal model are calculated and suitable parameters of the converter controllers are obtained to ensure dynamic stability [37-40]. The adopted control parameters of the tested system are listed in Table I.

\section{A. Performance Evaluation of the Proposed Control Strategy}

\section{1) Symmetrical Solid Fault at String Cable}

To test the proposed controller during an offshore AC fault and after fault isolation, a solid three-phase fault F1 is applied at the string cable $\mathrm{Cab}_{7}$ at $t=0.3 \mathrm{~s}$ and is isolated by breaker $B_{S 1}$ at $t=0.55 \mathrm{~s}$.

As shown in Fig. 5 (a), the offshore AC voltage collapses after the fault. For each converter, the $q$-axis current $i_{w q}^{+}$is quickly increased according to (5) to actively provide fault current whereas the $d$-axis current $i_{w d}^{+}$reduces to avoid converter overcurrent damage, as displayed in Fig. 5 (b), (e), and (i).
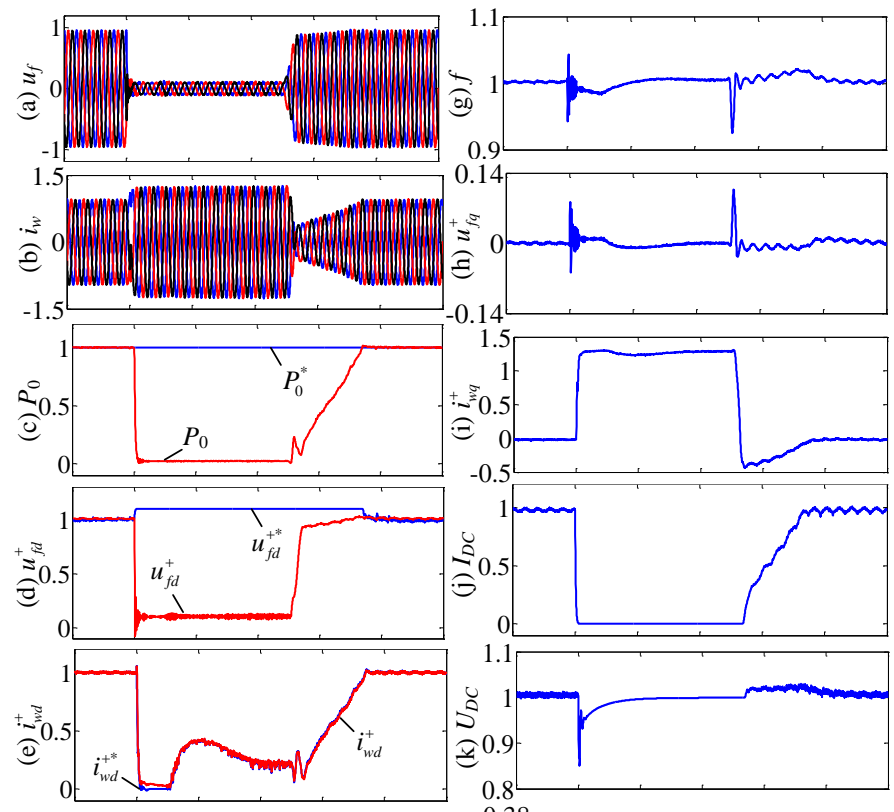

3
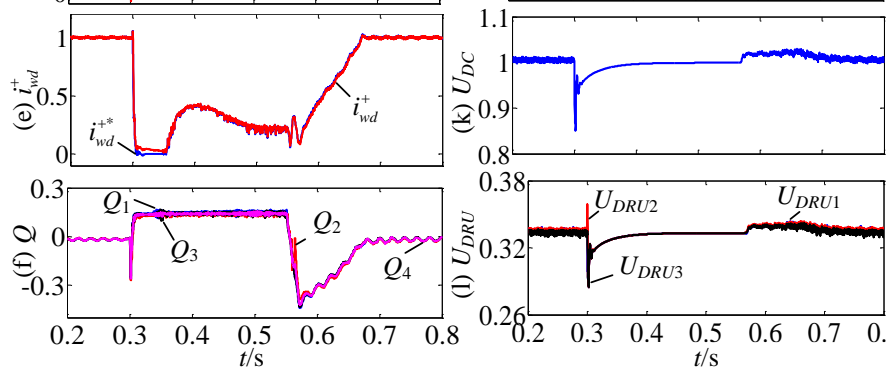

\section{8}

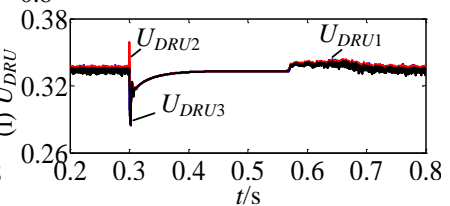

Fig. 5. Simulation results during symmetrical solid fault F1: (a) three-phase voltages, (b) three-phase currents, (c) active power, (d) $d$-axis voltage, (e) $d$-axis current, (f) reactive power, (g) frequency, (h) $q$-axis voltage, (i) $q$-axis current, (j) DRU-HVDC link current, (k) DRU-HVDC link voltage, and (l) DRU voltages.

After the fault initiation, the active power control loop saturates and sets the offshore voltage reference $u_{f d}^{+*}$ at 1.1 p.u., as shown in Fig. 5 (c) and (d). The $d$-axis voltage control loop also saturates during the fault and the converters operate on current limiting mode. After the fault is isolated by $B_{S 1}$ at $t=0.55$ s, the offshore voltage is gradually restored, as seen from Fig. 5 (a) and (d). Following the fault isolation and the offshore voltage restoration, the active power transmission gradually resumes, Fig. 5 (c) and (j).

During the entire simulation scenario, the reactive power is shared among the WT converters and the offshore frequency is largely controlled around the rated value of $50 \mathrm{~Hz}$, as shown in Fig. 5 (f) and (g), respectively.

The DC link voltage of the DRU-HVDC slightly drops following the fault and gradually restores, as can be seen in Fig. 5 (k). In addition, the three DRUs always share the HVDC link voltage, as displayed in Fig. 5 (1).

Fig. 5 demonstrates the WT converters automatically operate on current limiting mode during the fault and can provide fast fault current response, which enables the overcurrent and differential protection and avoids communication between the WTs and the offshore protection breakers, as will be discussed in Section V.B.

\section{2) Asymmetrical Solid Fault at String Cable}

In this scenario, phases $a$ and $b$ are short-circuited at the middle of the string cable $\mathrm{Cab}_{7}$ (F1, Fig. 1) at $t=0.3 \mathrm{~s}$ and breaker $B_{S 1}$ opens at $t=0.55 \mathrm{~s}$ to isolate the fault.

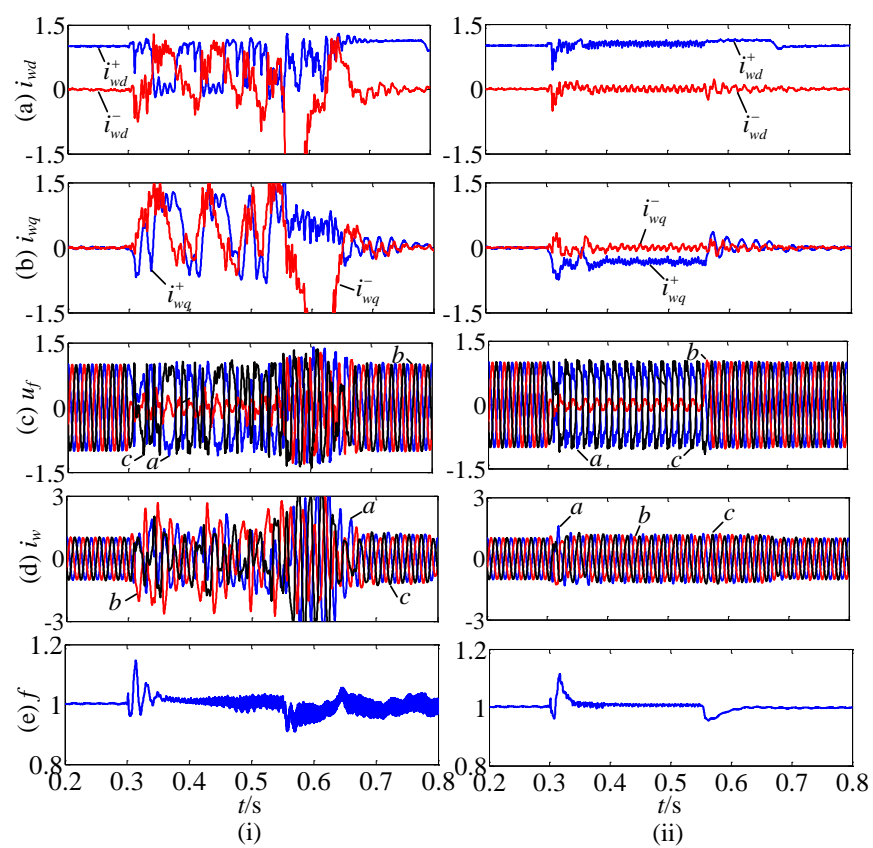

Fig. 6. Simulation results during asymmetrical solid fault F1 (i) without and (ii) with negative-sequence current controller: (a) positive- and negative-sequence $d$-axis currents, (b) positive- and negative-sequence $q$-axis currents, (c) threephase voltages, (d) three-phase currents, and (e) offshore frequency.

Fig. 6 compares the waveforms without and with negativesequence current controllers. As can be seen from Fig. 6, without the negative-sequence current controller, the converter loses the control of its current resulting in significant overcurrent whereas the proposed control strategy effectively regulates the positive- and negative-sequence $d$ - and $q$-axis currents with the negative-sequence current controlled at around zero. Thus, the proposed controller ensures the WT converters to remain operational during the fault to actively provide fault currents to enable fault detection. As displayed in Fig. 6 (e), the 
This paper is a post-print of a paper submitted to and accepted for publication in IEEE Transaction on Industrial Electronics and is subject to Institution of Electrical and Electronic Engineering Copyright. The copy of record is available at IEEE Xplore Digital Library.

negative-sequence current controller also improves the offshore frequency controllability during asymmetrical faults.

3) Reduced DC Voltage Operation

In the event of cluster cable faults, the DRU-HVDC link is able to operate with reduced DC voltage to resume wind power transmission.

After a symmetrical fault F2 applied at the cluster cable at $t=0.3 \mathrm{~s}$ as listed in Table II, the WT converters operate on current control mode while both the active power and $d$-axis voltage loops saturate, as aforementioned.

TABLE II

Timetable of the Reduced DC Voltage Operation.

\begin{tabular}{l|l}
\hline \hline \multicolumn{1}{c|}{ Time } & \multicolumn{1}{|c}{ Events } \\
\hline $0-0.3 \mathrm{~s}$ & Normal operation \\
\hline $0.3 \mathrm{~s}$ & Symmetrical fault occurs at cluster cable $C a b_{1}(\mathrm{~F} 2$, Fig. 1) \\
\hline $0.55 \mathrm{~s}$ & Circuit breaker $B_{C 1}$ opens \\
\hline $0.65-0.7 \mathrm{~s}$ & Onshore MMC reduces DRU-HVDC voltage \\
\hline \hline
\end{tabular}
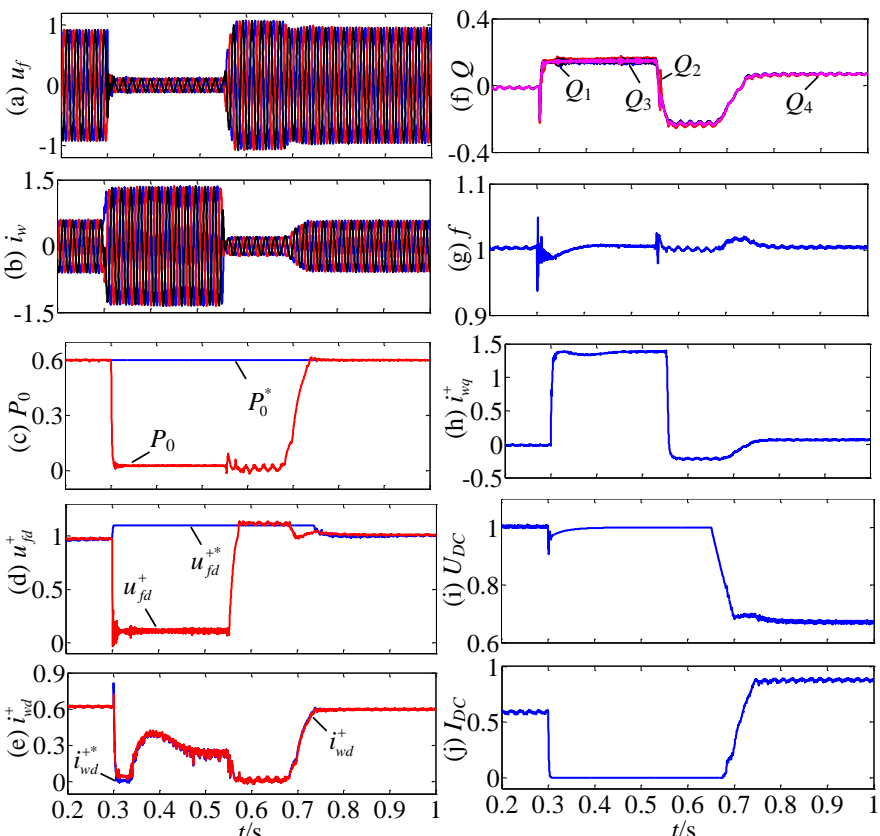

Fig. 7. Waveforms of reduced DC voltage operation during symmetrical solid fault F2: (a) three-phase voltages, (b) three-phase currents, (c) active power, (d) $d$-axis voltage, (e) $d$-axis current, (f) reactive power, (g) frequency, (h) $q$-axis current, (i) DRU-HVDC link voltage, and (j) DRU-HVDC link current.

After the fault is isolated by $B_{C 1}$ at $t=0.55 \mathrm{~s}$, the offshore voltage gradually restores as seen from Fig. 7 (a). However as DRU 1 is disconnected from the wind farm by breaker $B_{C 1}$ with zero DC voltage output, the total DC voltage on the offshore HVDC converter side is only formed by DRUs 2 and 3 and is now lower than the onshore DC voltage controlled by the hybrid MMC station. To ensure continued power transmission, the onshore hybrid MMC ramps down the DRU-HVDC link voltage from 1 p.u. to 0.67 p.u. during (0.65-0.7 s) as displayed in Fig. 7 (i). The power transmission gradually resumes as can be seen from Fig. 7 (c). Due to the reduced DC voltage, the DC current of the DRU-HVDC link is increased from 0.6 p.u. to 0.9 p.u. to restore power transmission, Fig. 7 (j).

With the proposed control scheme, the system is robust to the cluster cable fault, where the DRU-HVDC link operates with reduced DC voltage, and the WT converters can automatically restore normal operation.

\section{B. Performance Evaluation of Proposed Protection Scheme}

1) Overcurrent Protection During Symmetrical Solid Fault

The overcurrent protection scheme is assessed during symmetrical solid fault F2 applied at cluster cable $C a b_{1}$, as discussed in Section V A 3).

The fault currents provided by the WT converters (1.3 p.u.) feed to the fault through the circuit breaker $B_{C 1}$ and thus $B_{C 1}$ experiences overcurrent (3.9 p.u.) as shown in Fig. 8. (a), which is in agreement with (16). Thus, instantaneous overcurrent relay can be used to detect the fault, where the overcurrent protection operates instantaneously when the absolute value of one of the phase currents exceeds the pickup value. High pass filter is used to take out high frequency components of the measured currents. The pickup setting is selected so that the relay will operate for all faults in the cable sections for which it is to provide protection while mal-tripping during normal operation is avoided [41-43]. The instantaneous pickup current is thus set below the minimum fault current but greater than the full load current (e.g. 2.5 p.u.). Typically, the fault can be isolated by breakers in several tens milliseconds. However, to clearly demonstrate the system behaviors during faults, circuit breakers are commanded to open $250 \mathrm{~ms}$ after the fault initiation in this study. According to overcurrent fault detection, breaker $B_{C 1}$ is opened (assumed at $t=0.55 \mathrm{~s}$ for illustration) without the need for communication. All other breakers do not experience overcurrent and thus remain closed, Fig. 8 (b).

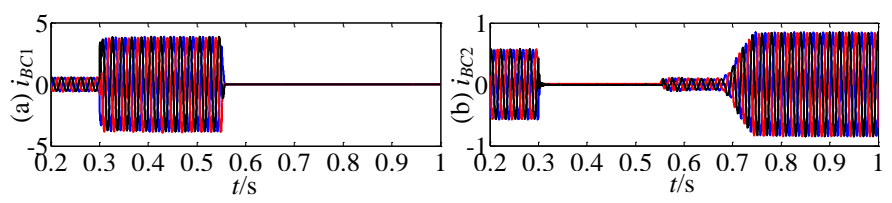

Fig. 8. Three phase currents flowing through circuit breakers during symmetrical cluster cable solid fault F2: (a) breaker $B_{C 1}$ on the faulty cable and (b) breaker $B_{C 2}$ on the healthy cable.

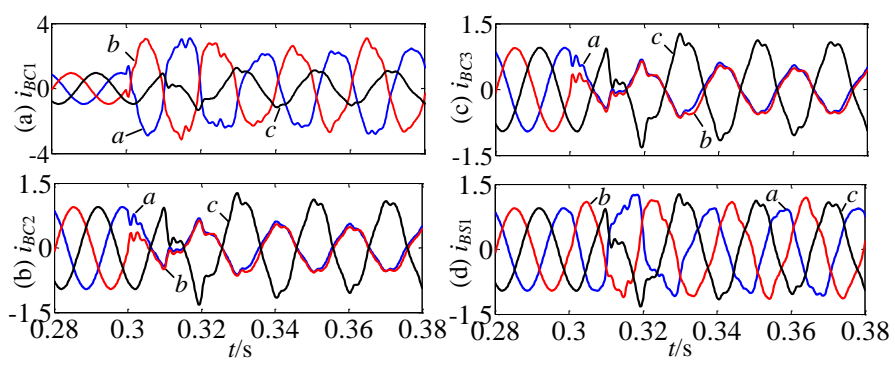

Fig. 9. Three phase currents flowing through circuit breakers during asymmetrical solid fault F2: (a) cluster breaker $B_{C 1}$, (b) cluster breaker $B_{C 2}$, (c) cluster breaker $B_{C 3}$, and (d) string breaker $B_{S 1}$.

\section{2) Overcurrent Protection During Asymmetrical Solid} Fault

An asymmetrical fault F2 occurs at the cluster cable at $t=0.3$ $\mathrm{s}$, where phases $a$ and $b$ are short-circuited. As shown in Fig. 9 (a), phases $a$ and $b$ of breaker $B_{C 1}$ experience overcurrent and $B_{C 1}$ is commanded to open to isolate the fault while the breakers on the healthy cables $B_{C 2}, B_{C 3}$, and $B_{S 1}-B_{S 5}$ remain closed as there is no significant overcurrent, as shown in Fig. 9 (b), (c), and (d). 
This paper is a post-print of a paper submitted to and accepted for publication in IEEE Transaction on Industrial Electronics and is subject to Institution of Electrical and Electronic Engineering Copyright. The copy of record is available at IEEE Xplore Digital Library.

3) Differential Protection During Symmetrical Solid Fault

A symmetrical solid fault (F3, Fig. 1) is applied at middle of the cluster interconnection cable $\mathrm{Cab}_{4}$ at $t=0.3 \mathrm{~s}$.

During normal operation, the currents flowing into and out of the cable are almost identical, leading to zero current difference. As aforementioned, the WT converters quickly provide fault currents after the fault. The currents both flow into $\mathrm{Cab}_{4}$, resulting in significant increase in the current difference, as shown in Fig. 10 (a). Once the current difference is over the protection threshold, circuit breakers $B_{B 13}$ and $B_{B 31}$ are both opened to isolate the fault and then the system automatically resumes normal operation. For illustration, $B_{B 13}$ and $B_{B 31}$ are opened at $t=0.55 \mathrm{~s}$ in this paper. As displayed in Fig. 10 (b), the currents flowing through the cluster breakers drop to zero after the fault (i.e. no overcurrent) and thus $B_{C 1}, B_{C 2}$, and $B_{C 3}$ remain closed.

4) Differential Protection During Asymmetrical Solid Fault

At $t=0.3 \mathrm{~s}$, an asymmetrical fault F3 (phases $a$ and $b$ shorecircuited) occurs at the cluster interconnection cable $\mathrm{Cab}_{4}$. For the faulty phases $a$ and $b$, the difference of currents flowing into and out of cable $\mathrm{Cab}_{4}$ significantly increases after fault as shown in Fig. 11 (a), and thus breakers $B_{B 13}$ and $B_{B 31}$ on the faulty cable are opened for fault isolation. The current differences on cluster interconnection cables $C a b_{5}$ and $C a b_{6}$ are around zero and are not shown in Fig. 11. The cluster and string breakers do not experience overcurrent, as displayed in Fig. 11 (b).

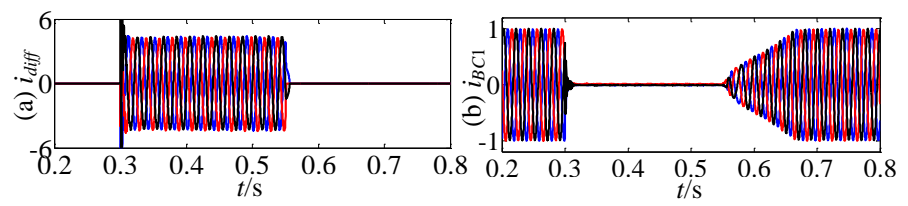

Fig. 10. Differential protection during symmetrical solid fault F3: (a) difference of the currents flowing into and out of cable $\mathrm{Cab}_{4}$ and (b) currents flowing through cluster breaker $B_{C 1}$.

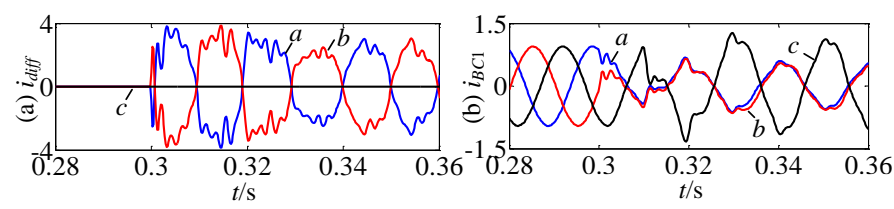

Fig. 11. Differential protection during asymmetrical solid fault F3: (a) difference of the currents flowing into and out of cable $\mathrm{Cab}_{4}$ and (b) currents flowing through cluster breaker $B_{C 1}$.

By injecting the voltage-error-dependent fault current, the WT converters quickly provided fault currents and this enables both overcurrent protection and differential protection. In addition, the proposed protection scheme can accurately open the corresponding breaker and enables offshore AC fault ridethrough operation of the system.

5) Fault Resistance Influences

In the solid fault test, the fault resistance $R_{f}$ is set at $3.6 \mathrm{~m} \Omega$ ( 0.001 p.u. at the base values of $1200 \mathrm{MW}$ and $66 \mathrm{kV}$ ). To assess the potential impact of fault resistance on the protection scheme, $R_{f}$ is increased to $3.6 \Omega$ (1 p.u.) and the currents flowing through circuit breakers are illustrated in Fig. 12 (i) which show similar results to those of the solid fault case in Fig. 8. With the fault resistance increased to $36 \Omega$ (10 p.u.), the currents $i_{B C 1}$ of the breaker $B_{C 1}$ on the faulty cable is reduced to 3 p.u., as the breakers on the healthy cables share more currents during the fault period, as displayed in Fig. 12 (ii). However, $i_{B C 1}$ is still sufficiently higher than the rated value. From the studies, it indicates that even with the short-circuit resistance varying in a wide range (0.001 10 p.u.), the breaker on the faulty cable always experiences significant fault current and thus can be protected using instantaneous overcurrent protection. The breakers on the healthy cables do not see overcurrent and will remain closed.

Similar tests are carried out for the differential protection as shown in Fig. 13. With large fault resistance of 10 p.u., the difference of the currents flowing into and out of the faulty cable $i_{\text {diff }}$ is reduced from 4.5 p.u. to 3 p.u. while the current $i_{B C 1}$ flowing through the breaker on the healthy cables are increased as seen in Fig. 13 (ii). However, $i_{\text {diff }}$ is around zero during normal operation and the fault value of 3 p.u. still provides sufficient margin to operate the breakers using differential protection.

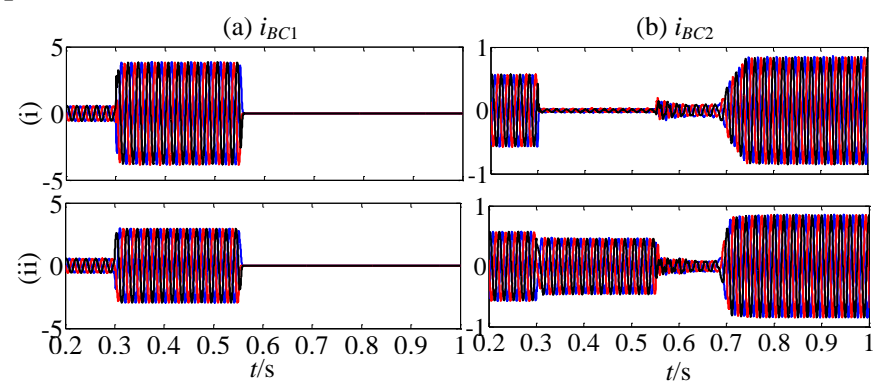

Fig. 12. Overcurrent protection during symmetrical cluster cable fault F2 with short-circuit resistance of: (i) 1 p.u. and (ii) 10 p.u.: (a) currents of breaker $B_{C 1}$ on the faulty cable and (b) currents of breaker $B_{C 2}$ on the healthy cable.

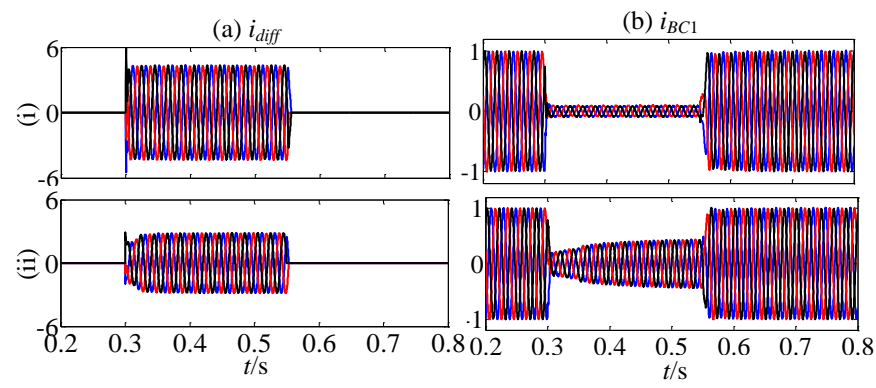

Fig. 13. Differential protection during symmetrical fault F3 with short-circuit resistance of: (i) 1 p.u. and (ii) 10 p.u.: (a) difference of the currents flowing into and out of cable $\mathrm{Cab}_{4}$ and (b) currents flowing through cluster breaker $B_{C 1}$.

\section{CONCLUSION}

A voltage-error-dependent fault current injection is proposed to regulate the WT current during offshore AC fault transients and quickly provide fault current to detect fault for OWFs connecting with DRU-HVDC system. Fault characteristics and fault protection requirements are addressed considering both symmetrical and asymmetrical AC faults. The proposed fault detection scheme combining overcurrent protection and differential protection can accurately open the corresponding circuit breakers during various fault cases, i.e. string fault, cluster fault, and interconnection cable fault. During cluster cable fault, the DRU-HVDC link operates with reduced DC voltage and the wind power transmission is automatically 
resumed, leading to improved system availability. With the proposed control and protection scheme, the WTs connecting with DRU-HVDC system can autonomously ride-through offshore AC faults and quickly resume normal operation.

\section{REFERENCES}

[1] E. Papatheou, N. Dervilis, A. E. Maguire, I. Antoniadou, and K. Worden, "A Performance Monitoring Approach for the Novel Lillgrund Offshore Wind Farm," IEEE Transactions on Industrial Electronics, vol. 62, pp. 6636-6644, 2015.

[2] L. Xu, B. R. Andersen, and P. Cartwright, "VSC transmission operating under unbalanced AC conditions - analysis and control design," IEEE Transactions on Power Delivery, vol. 20, pp. 427-434, 2005.

[3] A. Gandomkar, A. Parastar, and J. K. Seok, "High-Power Multilevel StepUp DC/DC Converter for Offshore Wind Energy Systems," IEEE Transactions on Industrial Electronics, vol. 63, pp. 7574-7585, 2016.

[4] R. Blasco-Gimenez, S. A.-. Villalba, J. Rodríguez-D'Derlée, F. Morant, and S. Bernal-Perez, "Distributed Voltage and Frequency Control of Offshore Wind Farms Connected With a Diode-Based HVdc Link," IEEE Transactions on Power Electronics, vol. 25, pp. 3095-3105, 2010.

[5] S. Seman, R. Zurowski, and C. Taratoris, "Interconnection of advanced Type 4 WTGs with Diode Rectifier based HVDC solution and weak AC grids," in Proceedings of the 14th Wind Integration Workshop,Brussels, Belgium, 20th-22nd Oct. , 2015.

[6] C. Prignitz, H. G. Eckel, S. Achenbach, F. Augsburger, and A. Schön, "FixReF: A control strategy for offshore wind farms with different wind turbine types and diode rectifier HVDC transmission," in 2016 IEEE 7th International Symposium on Power Electronics for Distributed Generation Systems (PEDG), 2016, pp. 1-7.

[7] T. H. Nguyen, D. C. Lee, and C. K. Kim, "A Series-Connected Topology of a Diode Rectifier and a Voltage-Source Converter for an HVDC Transmission System," IEEE Trans. Power Electron., vol. 29, pp. 15791584, 2014.

[8] R. Blasco-Gimenez, S. Anó-Villalba, J. Rodriguez-D'Derlée, S. BernalPerez, and F. Morant, "Diode-Based HVdc Link for the Connection of Large Offshore Wind Farms," IEEE Transactions on Energy Conversion, vol. 26, pp. 615-626, 2011.

[9] S. Bernal-Perez, S. Ano-Villalba, R. Blasco-Gimenez, and J. RodriguezD'Derlee, "Efficiency and Fault Ride-Through Performance of a DiodeRectifier- and VSC-Inverter-Based HVDC Link for Offshore Wind Farms," IEEE Transactions on Industrial Electronics, vol. 60, pp. 2401-2409, 2013.

[10]J. Guo, D. Jiang, Y. Zhou, P. Hu, Z. Lin, and Y. Liang, "Energy storable VSC-HVDC system based on modular multilevel converter," International Journal of Electrical Power \& Energy Systems, vol. 78, pp. 269-276, 2016/06/01/ 2016

[11]O. Kuhn, P. Menke, R. Zurowski, T. Christ, S. Seman, G. Giering, et al., "2nd generation DC grid access for offshore wind farms: HVDC in an AC fashion," CIGRE, Paris, pp. 1-7, 2016.

[12]M. A. Cardiel-Alvarez, J. L. Rodriguez-Amenedo, S. Arnaltes, and M. Montilla-DJesus, "Modeling and Control of LCC Rectifiers for Offshore Wind Farms Connected by HVDC Links," IEEE Transactions on Energy Conversion, vol. PP, pp. 1-1, 2017.

[13]L. Yu, R. Li, and L. Xu, "Distributed PLL-based Control of Offshore Wind Turbine Connected with Diode-Rectifier based HVDC Systems," IEEE Transactions on Power Delivery, vol. PP, pp. 1-1, 2017.

[14]R. Li and D. Xu, "Parallel Operation of Full Power Converters in Permanent-Magnet Direct-Drive Wind Power Generation System," IEEE Transactions on Industrial Electronics, vol. 60, pp. 1619-1629, 2013.

[15]J. Z. Zhang, T. Sun, F. Wang, J. Rodríguez, and R. Kennel, "A Computationally Efficient Quasi-Centralized DMPC for Back-to-Back Converter PMSG Wind Turbine Systems Without DC-Link Tracking Errors," IEEE Transactions on Industrial Electronics, vol. 63, pp. 61606171, 2016.

[16]L. P. Kunjumuhammed, B. C. Pal, R. Gupta, and K. J. Dyke, "Stability Analysis of a PMSG-Based Large Offshore Wind Farm Connected to a VSC-HVDC," IEEE Transactions on Energy Conversion, vol. 32, pp. 1166-1176, 2017.

[17]T. Kawaguchi, T. Sakazaki, T. Isobe, and R. Shimada, "Offshore-WindFarm Configuration Using Diode Rectifier With MERS in Current Link Topology," IEEE Transactions on Industrial Electronics, vol. 60, pp. 2930 2937, 2013
[18]R. Zeng, L. Xu, L. Yao, and B. W. Williams, "Design and Operation of a Hybrid Modular Multilevel Converter," IEEE Trans. Power Electron., vol. 30, pp. 1137-1146, 2015.

[19]N. R. Merritt, C. Chakraborty, and P. Bajpai, "New Voltage Control Strategies for VSC-Based DG Units in an Unbalanced Microgrid," IEEE Transactions on Sustainable Energy, vol. 8, pp. 1127-1139, 2017.

[20]W. Sanusi, M. A. Hosani, and M. S. E. Moursi, "A Novel DC Fault RideThrough Scheme for MTDC Networks Connecting Large-Scale Wind Parks," IEEE Transactions on Sustainable Energy, vol. 8, pp. 1086-1095, 2017.

[21]G. Pannell, D. J. Atkinson, and B. Zahawi, "Minimum-Threshold Crowbar for a Fault-Ride-Through Grid-Code-Compliant DFIG Wind Turbine," IEEE Transactions on Energy Conversion, vol. 25, pp. 750-759, 2010.

[22]S. Foster, L. Xu, and B. Fox, "Coordinated control and operation of DFIG and FSIG based Wind Farms," in 2007 IEEE Lausanne Power Tech, 2007, pp. 522-527.

[23]M. Nasiri and R. Mohammadi, "Peak Current Limitation for Grid Side Inverter by Limited Active Power in PMSG-Based Wind Turbines During Different Grid Faults," IEEE Transactions on Sustainable Energy, vol. 8, pp. 3-12, 2017.

[24]S. Bernal-Perez, S. Ano-Villalba, R. Blasco-Gimenez, and J. RodriguezD'Derlee, "Efficiency and Fault Ride-Through Performance of a DiodeRectifier- and VSC-Inverter-Based HVDC Link for Offshore Wind Farms," IEEE Trans. Ind. Electron., vol. 60, pp. 2401-2409, 2013.

[25]D. Xiang, J. C. Turu, S. M. Muratel, and T. Wang, "On-Site LVRT Testing Method for Full-Power Converter Wind Turbines," IEEE Transactions on Sustainable Energy, vol. 8, pp. 395-403, 2017.

[26]M. J. Hossain, H. R. Pota, V. A. Ugrinovskii, and R. A. Ramos, "Simultaneous STATCOM and Pitch Angle Control for Improved LVRT Capability of Fixed-Speed Wind Turbines," IEEE Transactions on Sustainable Energy, vol. 1, pp. 142-151, 2010.

[27]M. Firouzi, G. B. Gharehpetian, and S. B. Mozafari, "Application of UIPC to improve power system stability and LVRT capability of SCIG-based wind farms," IET Generation, Transmission \& Distribution, vol. 11, pp. 2314-2322, 2017

[28] Y. Wang, J. Meng, X. Zhang, and L. Xu, "Control of PMSG-Based Wind Turbines for System Inertial Response and Power Oscillation Damping," IEEE Transactions on Sustainable Energy, vol. 6, pp. 565-574, 2015.

[29]H. Dong, Z. Xu, P. Song, G. Tang, Q. Xu, and L. Sun, "Optimized Power Redistribution of Offshore Wind Farms Integrated VSC-MTDC Transmissions after Onshore Converter Outage," IEEE Transactions on Industrial Electronics, vol. PP, pp. 1-1, 2017.

[30]R. Blasco-Gimenez, N. Aparicio, S. Ano-Villalba, and S. Bernal-Perez, "LCC-HVDC Connection of Offshore Wind Farms With Reduced Filter Banks," IEEE Transactions on Industrial Electronics, vol. 60, pp. 23722380, 2013.

[31]J. Renedo, A. García-Cerrada, and L. Rouco, "Reactive-Power Coordination in VSC-HVDC Multi-Terminal Systems for Transient Stability Improvement," IEEE Transactions on Power Systems, vol. 32, pp. 3758-3767, 2017

[32]R. Li, L. Xu, and L. Yao, "DC Fault Detection and Location in Meshed Multiterminal HVDC Systems Based on DC Reactor Voltage Change Rate," IEEE Transactions on Power Delivery, vol. 32, pp. 1516-1526, 2017.

[33]R. E. Torres-Olguin, M. Molinas, and T. Undeland, "Offshore Wind Farm Grid Integration by VSC Technology With LCC-Based HVDC Transmission," IEEE Transactions on Sustainable Energy, vol. 3, pp. 899907, 2012.

[34]S. Dambhare, S. A. Soman, and M. C. Chandorkar, "Adaptive Current Differential Protection Schemes for Transmission-Line Protection," IEEE Transactions on Power Delivery, vol. 24, pp. 1832-1841, 2009.

[35] S. Li, W. Chen, X. Yin, and D. Chen, "Protection scheme for VSC-HVDC transmission lines based on transverse differential current," IET Generation, Transmission \& Distribution, vol. 11, pp. 2805-2813, 2017.

[36]R. Li, L. Xu, and D. Guo, "Accelerated switching function model of hybrid MMCs for HVDC system simulation," IET Power Electronics, 2017.

[37] G. O. Kalcon, G. P. Adam, O. Anaya-Lara, S. Lo, and K. Uhlen, "SmallSignal Stability Analysis of Multi-Terminal VSC-Based DC Transmission Systems," IEEE Transactions on Power Systems, vol. 27, pp. 1818-1830, 2012.

[38] Y. Li, G. Tang, T. An, H. Pang, P. Wang, J. Yang, et al., "Power Compensation Control for Interconnection of Weak Power Systems by VSC-HVDC," IEEE Transactions on Power Delivery, vol. 32, pp. 19641974, 2017. 
This paper is a post-print of a paper submitted to and accepted for publication in IEEE Transaction on Industrial Electronics and is subject to Institution of Electrical and Electronic Engineering Copyright. The copy of record is available at IEEE Xplore Digital Library.

[39]L. Zhang, L. Harnefors, and H. P. Nee, "Modeling and Control of VSCHVDC Links Connected to Island Systems," IEEE Transactions on Power Systems, vol. 26, pp. 783-793, 2011.

[40] S. Mortazavian, M. M. Shabestary, and Y. A. R. I. Mohamed, "Analysis and Dynamic Performance Improvement of Grid-Connected Voltage\&\#8211;Source Converters Under Unbalanced Network Conditions," IEEE Transactions on Power Electronics, vol. 32, pp. 81348149, 2017.

[41]F. B. Costa, A. Monti, and S. C. Paiva, "Overcurrent Protection in Distribution Systems With Distributed Generation Based on the Real-Time Boundary Wavelet Transform," IEEE Transactions on Power Delivery, vol. 32, pp. 462-473, 2017.

[42]Y. Wang and V. Dinavahi, "Real-time digital multi-function protection system on reconfigurable hardware," IET Generation, Transmission \& Distribution, vol. 10, pp. 2295-2305, 2016.

[43]B. Hussain, S. M. Sharkh, S. Hussain, and M. A. Abusara, "An Adaptive Relaying Scheme for Fuse Saving in Distribution Networks With Distributed Generation," IEEE Transactions on Power Delivery, vol. 28, pp. 669-677, 2013.

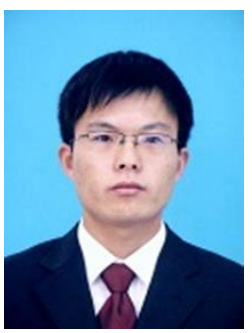

Rui Li received the M.S. and Ph.D degrees in electrical engineering from Harbin Institute of Technology, Harbin, China, in 2008 and 2013, respectively. Since 2013, he has been working as a research associate with University of Strathclyde in Glasgow, UK.

His research interests include HVDC transmision system, grid integration of renewable power, power electronic converters, and energy conversion.

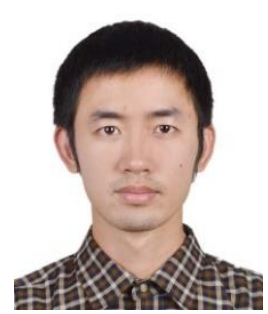

Lujie Yu received the B.S. and M.S. degree from North China Electric Power University (NCEPU), Beijing, China, in 2012 and 2015. He is currently pursuing the Ph.D degree in Electronic \& Electrical Engineering, University of Strathclyde, Glasgow, UK.

His research interests include HVDC transmision system and wind power integration.

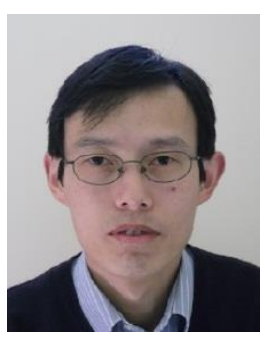

Lie Xu (M'03-SM'06) received the B.Sc. degree in Mechatronics from Zhejiang University, Hangzhou, China, in 1993, and the Ph.D. degree in Electrical Engineering from the University of Sheffield, Sheffield, UK, in 2000.

$\mathrm{He}$ is currently a Professor at the Department of Electronic \& Electrical Engineering, University of Strathclyde, Glasgow, UK. He previously worked in Queen's University of Belfast and ALSTOM T\&D, Stafford, UK. His research interests include power electronics, wind energy generation and grid integration, and application of power electronics to power systems. 